\title{
A Violência Doméstica na Adolescência, sob o olhar da Enfermagem e da Psicologia
}

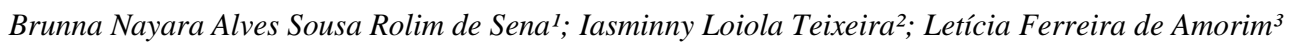

\begin{abstract}
Resumo: A violência é inerente à evolução da sociedade em toda a sua história. Dentre os tipos de violência, a doméstica representa toda e qualquer ação ou omissão que prejudique o bem-estar, a integridade física, psicológica ou a liberdade e o direito ao pleno desenvolvimento de um membro da família. Este tipo de violência ocorre ainda sob uma perspectiva oculta, dentre os demais tipos de violência. Atualmente, esta é considerada um problema de saúde pública, ressaltando, assim, a importância de salientar a atuação do profissional enfermeiro(a), bem como do psicólogo(a) diante deste quadro. Tais profissionais de saúde, bem como os seus processos de trabalho, devem ser bem instrumentalizados e respaldados teoricamente para que se torne possível compreender e interferir nesta problemática social, conforme às suas múltiplas formas de manifestações, sendo possível clarificar a partir deste estudo, a necessidade de incluir este tema na formação dos profissionais supracitados, no sentido de capacitá-los no desenvolvimento de práticas e cuidados integrais, junto a esta problemática, haja vista, a inserção dos mesmos no modelo de saúde que visa a perspectiva da integralidade e do cuidado do ser. Nesse cenário, evidencia-se a necessidade da elaboração de medidas intervencionistas, galgadas na vigilância, assistência e ensino de novas práticas educativas que forneçam subsídios e saberes necessários às práticas destes profissionais mediante as vivências, no contexto de violência doméstica, por exemplo, experienciadas na adolescência.
\end{abstract}

Palavras-chave: Adolescência; Violência Doméstica; Enfermeiro(a), Psicólogo(a)

\section{Domestic Violence in Adolescence, from the perspective of Nursing and Psychology}

\begin{abstract}
Violence is intrinsic in the evolution of society throughout its history. Among the types of violence, domestic violence represents any act or omission that damages the welfare, physical or psychological integrity or freedom and the right to the full development of a family member. This type of violence still occurs under a hidden perspective, among other types of violence. Currently, this is considered a public health problem, emphasizing, therefore, the importance of emphasizing the work of the nurse professional, as well as of the psychologist before this picture. Such health professionals, as well as their work processes, should be well instrumented and theoretically supported so that it becomes possible to understand and interfere in this social problematic, according to its multiple forms of manifestations, being possible to clarify from this study, the necessity to include this theme in the training of the above-mentioned professionals, in order to enable them in the development of comprehensive practices and care, along with this problem, given their inclusion in the health model that aims at the perspective of integrality and care of the to be. In this scenario, it is evident the need to elaborate interventionist measures, based on vigilance, assistance and teaching of new educational practices that provide the necessary subsidies and knowledge to the practices of these professionals through the experiences, in the context of domestic violence, for example, experienced in the adolescence.
\end{abstract}

Key words: Adolescence; Domestic violence; Nurse; Psychologist;

\footnotetext{
1 Graduada em Enfermagem na Faculdade do Valo do Jaguaribe (FVJ). Especialista em Educação Permanente em Saúde na Universidade Federal do Rio Grande do Sul (UFRGS). Especializanda em Gestão em Políticas Públicas e Saúde Coletiva na Universidade Regional do Cariri (URCA).E-mail: brunnarolim23@gmail.com.

2 Graduada em Psicologia no Centro Universitário Leão Sampaio (UNILEAO). Especialista em Psicologia Aplicada à Educação na Universidade Regional do Cariri (URCA). Membro do Laboratório de Avaliação Psicológica do Cariri (LAPSIC). E-mail: iasminnyloiolapsi@gmail.com.

3 Graduada em Enfermagem na Universidade Regional do Cariri (URCA). Residência Integrada em Saúde da Família e Comunidade pela Escola de Saúde Pública do Ceará (ESPCE). Email: leticiaamorim11@ @otmail.com.
} 


\section{Introdução}

A violência é inerente à evolução da sociedade em toda a sua história. Dentre os tipos de violência, a doméstica representa toda e qualquer ação ou omissão que prejudique o bem-estar, a integridade física, psicológica ou a liberdade e o direito ao pleno desenvolvimento de um membro da família (SALIBA et al., 2007).

Tudo pode ser principiado com a "sutileza" de um discurso invasivo e destruidor, infiltrado na rotina do próprio lar, resultando processualmente em formas grotescas e eminentemente agressivas. Este tipo de violência ocorrida é ainda uma face oculta, dentre os demais tipos de violência. A aparente proteção conferida pela família mantém escondida a prática de várias violações de direitos.

Dentro desse contexto citado anteriormente, a Organização Mundial de Saúde ressalta que existem quatro variedades reconhecidas como violência doméstica contra criança e adolescente: abuso físico, sexual, emocional e negligência (WHO, 2002).

De acordo com o Ministério da Saúde, a violência doméstica está inclusa no amplo entendimento de violência intrafamiliar, repercutindo desde simples alterações cutâneas até casos graves de internação e necessidade urgente de procedimento cirúrgico. No entanto, na prática esses conceitos adequados em categorias se entrelaçam e misturam-se, agravando ainda mais o quadro no qual o adolescente é acometido (BRASIL,2002).

Nesse sentido, torna-se importante relembrar que a prática da punição física esteve sempre presente na história pelo menos no mundo ocidental. Passou a ser combatida por algumas sociedades, como ocorreu no Brasil a partir das décadas de 1980 e 1990, com a criação do ECA (Estatuto da Criança e do Adolescente). A criança e o adolescente passaram a ser vistos e valorizados como sujeitos de direitos (ANDRADE et al., 2011).

A configuração dessa problemática perpassa aspectos políticos, econômicos, morais, legais, psicológicos e individuais. Entretanto, a família deve representar o espaço prioritário e o alicerce onde se estabelecem as oportunidades de socialização, bem-estar e proteção nas relações humanas. Porém, nem sempre isso acontece (MARTINS et al., 2007).

Esse fato pode ser exemplificado a partir do levantamento que foi realizado pelo Ministério da Saúde no ano de 2002, referindo-se às agressões que representaram a primeira causa de morte de jovens entre 5 e 19 anos de idade, sendo que a maior parte dessas agressões 
aconteceram especificamente no ambiente doméstico, evidenciando assim, a proliferação da violência doméstica (MARTINS,2010).

No contexto de atendimento em unidades básicas de saúde, a violência doméstica em adolescentes também está presente. Os profissionais de saúde devem estar atentos a essaquestão, observando os limites da violência doméstica, seu diagnóstico e as diversas maneiras de lidar com essa realidade.

Assim sendo, torna-se evidente a inter-relação desta problemática com o agravamento do processo saúde-doença. Nesse contexto, é essencial enfatizar que o profissional de saúde não pode ficar alheio a essa realidade ao passo que deve conhecer especificamente todas as diretrizes que norteiem esta problemática e de modo específico.

$\mathrm{O}$ adolescente ainda tem sido referido sempre limitado a uma definição conceitual relacionada mais aos aspectos biológicos de vivências orgânicas do que a articulação de suas várias dimensões (RESSEL et al., 2009). Por isso é essencial mencionar a formação da própria personalidade e a construção do caráter deste futuro adulto, sendo pertinente inferir as políticas que possam, quando aplicadas, constituir formas claras e autênticas que impliquem na promoção da saúde e que minimizem as possibilidades de comportamentos hostis e/ou sequelas maisagravantes.

Nesse sentido, pode-se considerar a Estratégia Saúde da Família como um espaço importante para a promoção da saúde do público adolescente visto ser esse um período da vida marcado pela vulnerabilidade, onde se evidencia a necessidade de estratégias direcionadas às demandas e agravos específicos dessa faixa etária. O investimento em ações voltadas à saúde e participação dos adolescentes nos serviços de saúde na Atenção Básica deve ser realizado, contribuindo para melhoria da qualidade de vida e conseqüentemente modificação do perfil de saúde da população (SLVA,2010).

Entretanto, a crescente necessidade de atendimento adequado a estas vítimas de violência que chegam aos serviços de saúde, evidencia cada vez mais a intensa debilidade estrutural do sistema de saúde e dificuldades de seus profissionais no atendimento e acompanhamento dessas pessoas. Tudo isso contribui para a reincidência e agravamento de casos (SOUZA et al., 2009).

Não é só analisar o fato em si, é atentar para repercussões futuras, considerando que o impacto de toda ação violenta pode acarretar danos vitalícios. Tendo esse enfoque, destaca-se a relevância de um profissional que conheça o regimento que amparam os adolescentes em 
vigor, para que assim suas ações possam ser norteadas, respaldas e atuantes na prestação de serviço com base essencialmente na prevenção, promoção, recuperação e reabilitação da saúde.

Os códigos de ética dos profissionais da Atenção Básica passaram por uma valiação a fim de observar como é trabalhada a temática. E foi possível percwber a partir desta observação que não documento algum que trate deste assunto de forma clara. Todavia, alguns artigos fazem mençaõ à obrigação que estes profissionais têm de zelar pela saúde,

dignidade e integridade humana. Assim, as normas específicas de cada profissão prevêem, mesmo que implicitamente, a necessidade que os trabalhadores da área de saúde têm de denunciar e estarem a par de toda e qualquer situação deste tipo de violência na sua área de abrangência (SALIBA et al., 2007).

De acordo com Art. $8^{\circ}$ do Código de Ética do Psicólogo (2015), no contexto de atendimento não eventual de adolescente ou interdito, o profisisonal da Psicologia deve obter autorização de ao menos um de seus responsáveis. Caso nenhum dos responsáveis possam se fazer presente ao momento da consulta, o atendimento deve ser realizado, mas apenas se for comunicado às autoridades competentes somente o essencial, para que todos os direitos do adolescente possam ser preservados. Além disso, O psicólogo responsabilizar-se-á pelos encaminhamentos que se fizerem necessários para garantir a proteção integral do sujeito em questão.

Conforme Araújo e Oliveira (2009) a Resolução do Conselho Nacional de Educação CNE/CES n ${ }^{\circ}$ 03/2001, mencionada expressamente na Resolução COFEN n 271/2002 prevê, na formação do enfermeiro, a capacidade de diagnosticar e solucionar problemas de saúde, intervir no processo saúde-doença, com a finalidade de proteger e reabilitar a saúde, na perspectiva da integralidade da assistência e integração da enfermagem as ações multiprofissionais.

Dessa forma, pode-se perceber que tais profissionais de saúde, bem como os seus processos de trabalho, devem ser bem instrumentalizados e respaldados teoricamente para que possa compreender e interferir nesta problemática social conforme as suas múltiplas formas de manifestação.

Os cuidados dos profissionais da Enfermagem e da Psicologia às vítimas de violência doméstica, que vivenciam a adolescência, devem ser planejados com o propósito de promoverem segurança, acolhimento, respeito e suporte nas diversas situações que estes jovens experienciam. 
Asssim, refletir sobre os seus papéis profissionais na vida desses sujeitos, pautados nos instrumentos básicos destas duas áreas da saúde, nas políticas públicas de saúde e na legislação vigente é fundamental para a proteção das vítimas e prevenção de agravos futuros.

Diante do exposto, pode-se perceber que é de suma importância o enfermeiro(a) e o psicólogo(a) estarem a par das políticas que norteiam o SUS (Sistema Único de Saúde) e especificamente, os pertencentes à atenção básica, pois trabalham diretamente baseados na territorialização, principalmente o enfermeiro(a).

Estes profissionais precisam se inteirar dos posicionamentos relatados diante desta problemática milenar, porém ocultada e ignorada quanto aos poucos índices probabilísticos, identificação de casos (agredidos e agressores), e condutas adotadas mediante o confronto com situações até então silenciosas e quase sempre estarrecedoras.

É importante identificar todos os fatores que conduzem o tipo de assistência executada para que haja ações mais norteadoras que venham a intervir nos pontos cruciais da cadeia de violência, para que possam ser realizadas reflexões a respeito da atuação destes profissionais nos cuidados que devem ser prestados às vítimas com vistas a estabelecer uma relação de cuidado mais eficaz, qualificando assim a assistência prestada.

Portanto, este estudo possibilitará ao leitor conhecer melhor a atuação do enfermeiro(a) e do psicólogo(a) frente aos adolescentes vítimas de violência doméstica, bem como identificar algumas estratégias utilizadas pelos enfermeiros(as) e psicólogos(as) na assistência aos adolescentes vítimas de violência doméstica, como também descrever as fragilidades/dificuldades apontadas para implementação do atendimento ao adolescente vítima de violência doméstica, além de clarificar algumas noções concernentes à inserção do adolescente na ESF e nas políticas públicas que o amparam no âmbito daviolência.

\section{Metodologia}

A abordagem qualitativa e teórica, é a que fundamenta tal estudo. De acordo com Minayo (2007), esse caráter metodológico responde a questões muito particulares, pelo fato de o ser humano se distinguir não apenas por agir, mas também por pensar sobre o que faz, bem como por interpretar suas ações dentro e fora da realidade vivida, com o apoio dos compartilhamentos dos que estão inseridos nos mesmos contextos experienciados.

Durante este percurso do estudo, procurou-se conhecer com maior intensidade a 
chegada do adolescente, vítima de violência doméstica, nas ESF e o atendimento destes por meio dos conhecimentos trabalhados na Enfermagem e na Psicologia, inseridos na logística do Sistema Único de Saúde, por meio da fundamentação em textos clássicos e contemporâneos, atribuindo, dessa forma, a este artigo um aspecto teórico inerente.

No que tange aos objetivos, pode-se verificar que este artigo respalda-se em uma análise exploratória, pelo fato de tornar a temática mais clara e possibilitar a construção de hipóteses em cima de tal estudo, bem como favorece também um contato mais próximo com o objeto de estudo.

O presente estudo foi desenvolvido com base na pesquisa bibliográfica, que de acordo com Gil (2009) volta-se à utilização de materiais já existentes que, por sua vez, já foram fundamentados e respaldados em estudos científicos no momento em que foram desenvolvidos. Pelo fato desta pesquisa ter esta abordagem, foram utilizados livros, artigos e textos em geral com embasamento científica, obviamente.

Nesse sentido, para a construção deste estudo foram utilizados sites como: Scielo, Google Acadêmico e Pepsico, sendo que as palavras-chave utilizadas foram: Violência doméstica, Enfermagem, Psicologia, Atendimento nas ESFS e alolescentes vítimas de violência. Foram utilizados, também, alguns textos clássicos, tendo em vista a relevância dos mesmos para a construção teórica desse trabalho. Todo o estudo foi realizado no período de 2015 a 2017.

\section{A Inserção do Adolescente na ESF e as Políticas Públicas que o amparam no âmbito da Violência.}

Atualmente, a Organização Mundial da Saúde define os adolescentes como pertencentes à faixa etária de 10 a 19 anos e os jovens como pessoas de 15 a 24 anos. Já para o Estatuto da Criança e do Adolescente (Lei no 8.069 de 13/07/1990) o adolescente é o indivíduo que se encontra entre a faixa etária de 12 e 18 anos deidade. Etimologicamente o termo "adolescência" vem do latim adolescere, em que ad significa "para" e olescere significa "crescer", tornando claro que é um processo de desenvolvimento e crescimento que envolve mudanças (TRAVESSO E PINHEIRO, 2002).

Assim, à primeira vista, a adolescência se apresenta como uma categoria vinculada à idade, portanto refere-se à biologia, ao estado e à capacidade do corpo. No entanto o 
desenvolvimento do adolescente não se esgota nas diversas e importantes mudanças que acontecem no âmbito biológico e fisiológico, ele também comporta várias significações superpostas construídas conforme o seu contexto sócio-historico. Dessa forma, além das mudanças biológicas, também ocorrem mudanças de papéis, de idéias e de atitudes (MARTINS et al., 2003)

Na ótica do paradigma biomédico é acentuado o sentido de adolescência na perspectiva desenvolvimentista, considerando uma etapa de transição entre a infância e a idade adulta, entendendo como natural e universal esta mudança, independentemente das condições concretas de existência dosujeito.

Ao caracterizar a adolescência como um estágio do desenvolvimento, deixa-se pouco espaço para as relevantes influências do meio. Assim, a família e os amigos têm papel crucial na formação códigos de valores próprios resultantes também da interação social e de escolha dos elementos adquiridos na infância que em conjunto contribuição para a formação de um novo adulto (PRATTA e SANTOS, 2007).

De acordo com Davim et al. (2009) para os adolescentes, a família é a sua referência na qual está envolvida sua história de vida. É, por excelência, lugar de construção da sexualidade desses jovens. É muito importante para a adolescência o modo como às famílias lidam com a afetividade, sexo, inter-relações, hierarquias, religião e as questões de gênero, assim como sua inserção na hierarquia social. O ambiente familiar deve ser de proteção, caracterizado por respeito, afetividade e relação de igualdade. Quando ocorrem lares desestruturados, autoritários, hierárquicos com rigidez de padrões morais e sexuais, esses adolescentes tornam-se mais suscetíveis à vivência de sofrimento eproblemas.

Muitas são as mudanças presentes nesta fase do desenvolvimento do ser humano, com isso surgem inúmeras características e peculiaridades, como transformações na relação de dependência com a família, escolha de um projeto de vida, inserção no mercado de trabalho, além de importantes mudanças físicas e mentais, articuladas a uma reorganização de identidade e papéis sociais.

É elementar atentar para a percepção de que essa fase deve ser conduzida de forma cuidadosa tendo em vista a grande vulnerabilidade na qual está atrelada, com diferentes contos com fatores de risco que podem ocasionar em alguns agravos à vida do sujeito.

Dessa forma, objetivando amenizar agravos, reduzir o contato com fatores de risco e promover a saúde do adolescente, ações em nível primário precisam ser desenvolvidas, sobretudo de cunho educativo, com o objetivo de estimular a autonomia dos sujeitos 
envolvidos, para que estes possam atuar como protagonistas no planejamento, na execução e na avaliação dessas tarefas.

Nessa perspectiva, pode-se considerar a ESF como um espaço importante para esta promoção da saúde do público adolescente visto ser esse um período da vida marcado pela vulnerabilidade, onde se evidencia a necessidade de estratégias direcionadas às demandas e agravos específicos dessa faixa etária. O investimento em ações voltadas à saúde e participação dos adolescentes nos serviços de saúde na atenção básica deve ser realizado, contribuindo para melhoria da qualidade de vida e conseqüentemente modificando o perfil de saúde da população, legalmente.

Com as garantias legais e, mais recentemente, com a aprovação da Política Nacional de Atenção à Saúde de Adolescentes e de Jovens (Brasil, 2007), a responsabilidade pelas ações integrais de saúde voltadas a essa população fica colocada na Atenção Básica, mais especificamente, na Estratégia de Saúde daFamília.

A política nacional da atenção básica conceitualmente favorece a atenção integral à saúde do adolescente trabalhando os diversos aspectos de suas vidas, através da garantia do acesso universal aos serviços de saúde, integralidade da atenção, desenvolvimento do vínculo entre famílias e equipe, e estímulo à participação popular (BRASIL, 2006).

Nesse contexto, pode-se entender participação como um processo que implica conquista, compromisso, envolvimento e compartilhamento, possibilitando ao indivíduo a formação de uma consciência critica sobre a realidade na qual está inserido e a partir disso este pode se tornar um ser autônomo e emancipado. Nesta concepção, insere-se umser cidadão, idealizado e almejado para a efetivação do projeto da promoção da saúde (MACHADO, VIEIRA, SILVA, 2010).

Todavia, de acordo com Henrique, Rocha e Madeira (2010) uma assistência primária de qualidade só pode ser efetivamente reconhecida se houver a presença de uma estrutura física adequada, equipamentos básicos e, essencialmente, recursos humanos habilitados. Pode-se observar que, na atualidade, a maioria das dificuldades vivenciadas na atenção à saúde do adolescente está associada à falta de habilidade das equipes em desenvolver ações que sanem as demandas básicas desse público.

A Política Nacional da Atenção Básica pode favorecer a atenção integral à saúde do adolescente trabalhando os diversos aspectos de suas vidas, por meio da garantia do acesso universal aos serviços de saúde, integralidade da atenção, desenvolvimento do vínculo entre famílias e equipe, e estímulo à participação popular (BRASIL, 2006). 
Entretanto, alguns pontos merecem ser discutidos sobre a realidade dos adolescentes na Atenção Básica. Torna-se interessante considerar que existe uma relativa ausência dos adolescentes nos serviços de saúde, no entanto, não se sabe afirmar se este fato se deve a pouca oferta de ações voltadas para eles ou à baixa procura dos mesmos, já que estes dois fatores estão interligados e se referem à forma como o serviço de saúde está estruturado, mostrando que ainda são incipientes as ações voltadas para a saúde do adolescente (FERRARI; THOMSON; MELCHIOR,2006).

As mudanças decorrentes da Constituição de 1988 e os resultados do processo de elaboração e aprovação do Estatuto da Criança e do Adolescente em 1990 postulam o fim das políticas de cunho repressivo e paternalista, uma vez que o Estatuto estabelece uma política de atendimento aos direitos da criança e do adolescente. Consequentemente, com a transição da ditadura à democracia, o paradigma corretivo dá lugar a um paradigma educativo, de caráter renovado, de direitos para a criança e o adolescente (RAPOSO, 2009).

Este código consolida os direitos básicos da população infantojuvenil e deixa claro em seu artigo $1^{\circ}$, claramente dispõe a doutrina da proteção integral, determinando a natureza tutelar dos direitos ali elencados, que predominarão sobre qualquer outro que possa prejudicá- lo (ECA, 1990).

Deixa claro também, em seu artigo 245, quando considera infração administrativa os casos em que o professor ou responsável por estabelecimento de atenção à saúde e de ensino fundamental deixar de comunicar à autoridade competente os casos de que tenha conhecimento, envolvendo suspeita ou confirmação de maus-tratos e/ou negligência contra a criança e o adolescente (ECA, 1990). Todavia, é de suma importância enfatizar que a comunicação sem as devidas cautelas pode trazer sérias conseqüências para a própria vítima, afastando-a definitivamente dos serviços de saúde.

Conforme expressa em todo o seu conteúdo, o ECA apresenta tipos penais aos atos praticados contra crianças e adolescentes, por ação ou omissão, e determinou medidas específicas aplicáveis a pais ou responsáveis na hipótese de maus-tratos, opressão ou abuso sexual. Anteriormente não existiam medidas específicas aplicáveis a pais ou responsáveis em situações de maus-tratos, opressão ou abuso sexual.

Segundo o MS (BRASIL, 2002, p.15) a notificação neste contexto é definida como:

\footnotetext{
"uma informação emitida pelo Setor Saúde ou por qualquer outro órgão ou pessoa, para o Conselho Tutelar, com a finalidade de promover cuidados sociossanitários voltados para a proteção da criança e do adolescente, vítimas
} 
de maus-tratos. $\mathrm{O}$ ato de notificar inicia um processo que visa a interromper as atitudes e comportamentos violentos no âmbito da família por parte de qualquer agressor. Não é e nem vale como denúncia policial".

A notificação deve ser acrescida à rotina das atividades de atendimento e ao quadro organizacional dos serviços preventivos e assistenciais. É preciso lembrar que o ECA estabelece multa pela não notificação, tanto para a instituição bem como a categoria em questão (ECA, 2017).

No cenário nacional mais recente foi criada a Portaria $\mathrm{N}^{\circ} 1.162,07$ de Julho de 2005, determinando que a Secretaria de Atenção à Saúde submetesse à Consulta Pública a minuta da Política Nacional de Atenção Integral à Saúde de Adolescentes e Jovens. Deu-se o processo de mobilização coletiva da sociedade para a construção preliminar de um artifício que respondesse às necessidades de saúde, consolidando de maneira efetiva a validação dos direitos concedidos (BRASIL, 2006).

Conforme Raposo (2009), essa respectiva política reflete uma nova linha de reflexão da atenção à saúde do adolescente, principalmente por evidenciar a integralidade da atenção em consonância com um dos princípios do SUS, o que pressupõe o atendimento integral com prioridade para as atividades preventivas, sem prejuízo dos serviços assistenciais, e a organização de serviços para a execução dessas práticas de saúde, destacando a importância da promoção da saúde e a necessidade de estabelecer processos de trabalho intersetoriais e interdisciplinares.

Dessa forma, institucionaliza um novo olhar sobre o adolescente, apresentando arcabouço teórico que estimula a reflexão sobre novos conceitos, estratégias e ações na área de promoção da saúde voltada para esse grupo etário. Por conseguinte, ainda preconiza a atenção integral a esse segmento populacional, considerando as necessidades específicas de adolescentes e jovens, as características socioeconômicas e culturais da comunidade à qual pertencem, bem como as diferenças de gênero, raça ereligião. 
Em sua origem e manifestações, a violência é um fenômeno sociohistórico e acompanha toda a experiência da humanidade. Por longos períodos da história foi uma prática habitual, justificada e aceita pelas diferentes sociedades. Atos como o infanticídio, abandono em instituições, escravidão, exploração do trabalho infantil, além de mutilação de membros são registros e relatos freqüentes que denotam marcas que repercutem durante toda uma vida. São episódios espantosos diante da ótica de compreensão da natureza humana.

De acordo com a Organização Mundial de Saúde (OMS):

\footnotetext{
“A violência é definida como o uso da força física, do poder real ou ameaça, praticado contra si ou contra outra pessoa, ou ainda, contraum grupo ou uma comunidade, que resulte ou tenha possibilidade de resultar em lesão, morte, dano psicológico, deficiência de desenvolvimento ou privação. É compreendida também como uma violação dos direitos do ser humano, uma vez que é um meio aplicado para coagir ou submeter outra pessoa ao domínio sem seu consentimento" (BRASIL, 2005, pag. 28).
}

Segundo OMS, uma estimativa de 31 mil crianças e jovens menores de 15 anos foram vítimas de homicídios em 2002, principalmente em países não desenvolvidos e em fase de desenvolvimento. Partindo da premissa que as mortes por violência sejam os atos extremos, a magnitude da morbidade por este grupo de causa assumiria patamares mais elevados (PRIULI; MORAES, 2007).

Contudo, mesmo diante desta realidade as ações efetivadas diferem muitas vezes do que preconizam os protocolos. Isso fica claro quando estudos evidenciam que existe a subestimação da morbidade por violência se dá pela falta de diagnóstico por parte dos profissionais de saúde que, na sua maioria, encontram-se despreparados para identificar a violência e pela dificuldade de visibilidade do evento, acarretando ausência de notificação (OLIVEIRA et al., 2011).

Conforme Paludo (2008 apud OLIVEIRA et al. 2011) existem alguns fatores que são apontados como potencializadores desta problemática em nossa sociedade, tais como: descontrole emocional, falta de responsabilidade, sentimentos de culpa, uso de drogas pelo adolescente e/ou pelos pais, alcoolismo dos pais, falta de diálogo entre os membros da família, escassez econômica, precárias condições de vida, ausência de rede de apoio à família e conseqüências da violência estrutural existente nacomunidade. 
Pires e Miyazaki (2007) afirmam que vários estudos mostram que adolescentes submetidas à violência doméstica, quando comparadas às que não sofreram violência, são mais agressivas, têm baixa auto-estima, déficit de atenção, hiperatividade, dificuldade de relacionamento interpessoal, comportamento abusivo (serão também abusadores), baixo rendimento escolar, delinqüência, gravidez precoce, uso de drogas, capacidade cognitiva e de desenvolvimento da linguageminferiores.

Tendo em vista o contexto no qual está situada a problemática em questão, pode-se perceber que os reflexos da violência são claramente verificados no âmbito dos serviços de saúde, seja pelos custos que representam, seja pela complexidade do atendimento que demandam. Logo, esse setor tem importante papel no enfrentamento da violência doméstica em todos os seus aspectos (SALIBA et al., 2007).

Por conseguinte, a Atenção Básica representa a porta de entrada para abordar a violência, devido a proximidade e ampla cobertura, a partir do conceito de delimitação do território, mapeamento das áreas e microáreas estando sob a responsabilidade de uma equipe, funcionando assim como um espaço para identificação e notificação, sendo que esta quando efetivada corretamente pelo profissional de saúde poderá apontar a violência com maior visibilidade perante a sociedade, permitindo o dimensionamento epidemiológico do problema e a criação de políticas voltadas à sua prevenção.

Araújo e Rocha (2007) expressa que o trabalho em equipe, baseado na Política de Atenção Básica, tem como objetivo a obtenção de impactos sobre os diferentes fatores que interferem no processo saúde-doença. A ação interdisciplinar pressupõe a possibilidade da prática de um se reconstruir na prática do outro, ambos sendo transformados para a intervenção na realidade em que estão inseridos.

A legislação sobre maus-tratos no Brasil tem adotado como parâmetro o modelo americano. Isso se refere à obrigatoriedade de notificar estabelecida para profissionais, ao passo que também é dever encaminhar o caso notificado a um organismo designado em lei, cabendo punição legal ao profissional que assim não o fizer (LUNA; FERREIRA; VIEIRA, 2010).

Segundo a Política Nacional de Redução da Morbimortalidade por Acidentes e Violências, do Ministério da Saúde, a violência doméstica representa um problema de saúde pública e deve ser avaliada e notificada (SILVA et al., 2002). Os casos que passam a ser de conhecimento dos órgãos públicos de saúde, são de fundamental importâcia, pois a partir destes 
a violência passa a ser percebida de uma forma mais aprimorada, podendo ser estudada com a finalidade de amenizar as consequências de tal ato, como também permitir a criação de políticas públicas voltadas à sua prevenção (COSTA et al., 2009).

\section{O Enfermeiro como ator intervencionista no cenário da Violência Doméstica}

A violência doméstica de fato constitui um problema relevante de saúde pública e um desafio para o Sistema Único de Saúde (SUS) no que diz respeito à organização de serviços e gestão de recursos humanos.

De acordo com Souza et al. (2009) estudos têm reconhecido que os profissionais de saúde, pela posição que ocupam na prestação de serviços à população, são considerados essenciais na identificação de indivíduos e grupos populacionais de risco para a violência e para a execução de iniciativas que promovam a prevenção e as intervenções mais adequadas.

O crescimento da violência nos indica, de forma indiscutível, que as atividades, campanhas e esforços sobre a questão são ainda insuficientes. Mostram a necessidade de profissionais capacitados, sobretudo enfermeiros, capazes de reconhecer situações de violência nas famílias atendidas pelos serviços locais de saúde. Além disso, é necessário ampliar a visão diagnóstico-individualista para uma visão totalizante, passando, a família, a ter posição central no cuidado (SALCEDO-BARRIENTOS et al.,2011).

Desse modo, conforme Oliveira et al. (2011) para que no processo de trabalho do enfermeiro ele seja capaz de identificar e intervir nos casos de violência que se manifestam em graus variáveis e não apenas em atos extremos de homicídios, necessita-se que este profissional de saúde, bem como o processo de trabalho em saúde, seja instrumentalizado para que possa compreendê-lo nas suas múltiplas formas de manifestação.

As unidades de saúde têm potencial para identificar os casos de violência e o vínculo que mantém com a população é favorável nas ações de intervenção. Entretanto, os profissionais apresentam dificuldades para essa prática, tais como as relacionadas ao medo, à insegurança, à falta de profissionais capacitados, à falta de infraestrutura adequada e, principalmente, à de uma rede articulada para assistência às vítimas de violência (LIMA et al., 2009). 
Segundo Ferraz et al. (2009) o trabalho dos enfermeiros(as) voltado para as vítimas de violência precisa ser pensado de forma planejada, por meio das políticas públicas e dos conhecimentos técnicos da enfermagem, porque faz-se necessário passar para estas o sentimento de acolhimento, respeito e principalmente segurança, para que essas pessoas possam se sentir satisfeitas com relação às suas demandas pessoais. Por isso, é primordial a proteção e a prevenção de possíveis agravos futuros, levando-se em consideram a saúde física e mental destas vítimas.

O Ministério da Saúde reforça que os cuidados da enfermagem, no contexto citado anteriormente, precisam ser executados com segurança e com conhecimentos aprimorados, por parte do profissional, no âmbito das políticas de saúde para que os agravos futuros possam ser detectados de forma precoce. As vítimas devem ser orientadas sobre a violência, sobre o prognóstico desse contexto, como também sobre os recursos que estas têm, por direito, a favor da preservação da sua saúde, como por exemplo, o auxilio de uma equipe multiprofissional e o acesso aos mais diversos equipamentos sociais que estão inseridos na comunidade (BRASIL, 2002).

$\mathrm{O}$ ato de cuidar demanda dos profissionais da enfermagem:

\footnotetext{
"a utilização de instrumentos fundamentais para o exercício profissional, os quais são meios para que o cuidador atinja os objetivos propostos. Esses instrumentos envolvem a observação, o cuidado emocional, o toque terapêutico, o corpo, o bom senso, a liderança, o caráter humanitário, a solidariedade, a sensibilidade, a técnica, a relação educativa e as dimensões psicossociais e psicoespirituais" (SILVA; TORNELI; LACERDA, 2003, pag. 75).
}

FERRAZ et al. (2009) salienta que as vítimas de violência doméstica, quando procuram ajuda, comumente direcionam-se aos equipamentos sociais de saúde, o que facilita a construção de um contato mais próximo com os profissionais enfermeiros(as), já que estes são os responsáveis pelo processo de triagem, a fim de acolher o sofrimento de quem chega precisando de ajuda, podendo contribuir com o favorecimento da redução dos danos, bem como pode contribuir ainda com uma possível transformação no contexto social no qual a vítima está inserida.

Entretanto, segundo SALIBA et al. (2007) os profissionais dessa área têm uma tendência a subestimar a importância de um fenômeno e/ou cuidado que não seja voltado para o âmbito 
de uma lesão física, tornando uma espécie de exceção o fato de atentar-se para previnir ou até mesmo diagnosticar as causas primeiras das dores físicas. Esse fato pode estar associado à falta de preparo profissional, ou simplesmente, à decisão de não se envolver com os casos de mais singular.

Porém, é importante frisar que não basta apenas conscientizar-se dos cuidados atenciosos que é preciso ser exercidos com todas as pessoas que procuram um atendimento de enfermagem, faz-se necessário também deixar de lado os "a prioris" que podem surgir no momento do atendimento, como também torna-se primordial atentar-se para as capacitações e treinamento que precisam ser acolhidos por tais profissionais para que as situações de violência possam ser detectadas com mais humanidade e tecnicismo, no momento de uma atendimento, por exemplo, para que dessa forma passe a ser possível dar seguimento aos fluxos de atuação no âmbito dos danos, agravos e reabilitação das situação de violência vivenciadas em sociedade.

\section{A Importãncia do Psicólogo(a) frente ao atendimento de Adolescentes Vítimas de Violência Doméstica}

Pensar em violência hoje, em termos gerais, reflete em uma gama diversa de causas, consequências, objetivos, justificativas e muitas transformações, sendo estas positivas ou não. Haja vista a presença, em massa, de tal ato na contemporaneidade, realidade esta que, a depender da compreensão, o ato de ser violento ou de praticar a violência já faz parte do processo de sobrevivência humana, ao ser compreendida como uma defesa de algo ou de alguém, por exemplo (CESCA; BRASIL, 2004).

Em virtude de tal cenário social, é sabido que a o sujeito em sociedade nem sempre está preparado, muito menos apto a lidar com algumas mudanças de forma tão intensa ou até mesmo invasiva, como é o fato de enfrentar situações no contexto de violência doméstica, tendo como vítimas os adolescentes. Nesse sentido, levando-se em consideração a dificuldade de enfrentar e lidar com tais vivências que podem provocar rupturas no desenvolvimento do sujeito social trata-se de fundamental importância, a intervenção psicológica nesse cenário, ofertando suporte e acolhimento psicológico para com as vítimas, aos seus familiares e aos agressores, 
resguardando os direitos e deveres que lhes cabem, como também tais profissionais precisam está pautados no cumprimento e no dever do sigilo ético resguardado no código de ética destes.

De acordo com Silva (2003) o papel do profissional da psicologia, nesse âmbito da violência, fundamenta-se em uma espécie de interpretação dos fatos que estão inseridos na comunicação inconsciente que ocorre na dinâmica familiar e pessoal [...] O propósito é enfatizar e averiguar os aspectos psicológicos das pessoas envolvidas, referindo-se a questões afetivocomportamentais da dinâmica familiar, entrelaçadas nas relações processuais, podendo assegurar os entidireitos e o bem-estar da criança e/ou do adolescente, a fim de auxiliar o juiz na tomada de uma decisão que melhor atenda às necessidades dessas pessoas (SILVA, 2003).

É importante salientar, segundo Dutra (2008) que, pelo fato da violência doméstica ser um fenômeno social, não se pode olhar para o sujeito, que está precisando do atendimento psicológico, sem levar em consideração sua historia de vida e o meio no qual ele se insere. Mediante tal percepção foi possível pensar em um novo campo de atuação para o psicólogo, surgindo assim, o conceito de clínica ampliada, com a intenção de amplificar as diversas formas de atuação do profissional da psicologia, bem como pluralizar sua metodologia em diferentes espaços físicos.

O profissional da Psicologia que deseja atuar neste âmbito, citado anteriormente, precisa intervir para além da psicoterapia individual, com relação aos seus mecanismos de trabalho. Faz-se necessário também utilizar-se da terapia comunitária e de campanhas socioeducativas. Neste contexto, não é o sujeito quem procura o psicólogo e sim o contrário. A clínica ampliada objetivaoalcançar toda a comunidade, em termos de acolhimento e possíveis mudanças a partir das intervenções trabalhadas. (MURTA \& MARINHO, 2009).

Dessa forma, o papel do psicólogo(a) na clínica se relaciona muito mais com a atitude do profissional, do que com os espaços físicos no qual ele atua. Este profissional deve saber adaptar a postura clínica aos contextos nos quais ele atua, seja nos consultórios, nos hospitais, ou nas instituições governamentais, desenvolvendo um método no qual a escuta clínica deve ser ativa, podendo assim, possibilitar a criação de um ambiente terapêutico em diversos contextos, estando preparado para acolher o sujeito que se encontra imerso no sofrimento psíquico, independente do espaço físico no qual ele se encontra e do contexto vivenciado (DUTRA, 2008). 
No que diz respeito ainda à atuação do psicólogo(a) no contexto de violência relacionado ao público adolescente, este deve fundamentar - se em "criar um clima de segurança e aceitação afim de que a criança adquira confiança e comece a se comunicar" (ZAVASHI apud HABIGZANG, 2004, p.70), como também realizar ações que envolvam o sujeito e o seu ambiente para a superação dos conflitos internos e externos, através das intervenções clínica, a fim de proteger o adolescente, e fornecer subsídio ao mesmo, para que este possa desenvolver-se adaptando-se à sociedade e tendo uma melhor qualidade de vida.

Dessa forma, pode-se compreender que o psicólogo(a) deve realizar os seus trabalhos com a finalidade de reverter os sentimentos de desespero, desamparo, impotência, aprisionamento, isolamento e auto acusação que paralisam a vítima. $\mathrm{O}$ trabalho daquele precisa ocasionar mudanças positivas e progressivas na vida desta, objetivando evitar todo e qualquer obstáculo no processo de ressignificação desse sujeito, para que o futuro do mesmo passe a ser visto com esperança, motivando o adolescente a crescer cada vez mais com entusiasmo pela vida. (ZAVASCHI, apud HABIGZANG 2004, p.70-71)

Levando-se em consideração o que já foi exposto, pode-se concluir que o atendimento psicológico deve desenvolver as suas ações pautado na atenção psicossocial, já que este precisa ser operacionalizado por meio de um aglomerado de procedimentos técnicos especializados, objetivando estruturar ações de atendimento e de proteção a crianças e adolescentes, fornecendo-lhes condições para o fortalecimento da autoestima, o restabelecimento de seu direito à convivência familiar e comunitária em condições dignas de vida, além de facilitar a superação da situação de violação de direitos, podendo ressignificar a violência sofrida (CARMO; SAGAZ,2002)

\section{Considerações Finais}

As diferentes formas de violência e de violação de direitos quando associadas ao despreparo profissional no enfrentamento do problema, apontam a vigência de uma situação crítica em tempos considerados modernos em nossa sociedade.

O novo chegou para as diferentes castas brasileiras, entretanto a violência doméstica ainda representa uma faceta mal resolvida e um sério agravante, apresentando-se de forma milenar 
em nossa história, destacando assim o potencial efeito do fator social sobre o processo saúdedoença.

O desdobramento em uma cadeia de múltiplas faces apresenta essa problemática em representação ainda mais complexa. Por isso torna-se urgente a inserção do enfermeiro como agente capaz de intervir de forma proativa, trabalhando desde a correta identificação até a efetiva segurança dos possíveis encaminhamentos.

Considerado, pois, esta realidade, foi possível evidenciar que embora os enfermeiros ainda não tenham assistido adolescentes vítimas de violência, estes relataram dificuldades quanto ao tipo de abordagem desempenharia ao deparar-se com adolescentes vitimados e se veem em meio a conflitos relacionados a normas culturais, éticas e legais, o que requer conhecimento da legislação para uma assistência efetiva às necessidades das vitimas e das suasfamílias.

Ficou claro também a necessidade de incluir esse tema na formação do enfermeiro, no sentido de instrumentalizá-lo para uma prática integral junto a esta problemática, uma vez que, ainda que inseridos em um modelo de saúde com o processo de trabalho na perspectiva da integralidade e do cuidado, ao discursarem sobre o cotidiano de trabalho, apontaram para uma prática fragmentada.

Nesse cenário, evidencia-se a necessidade da elaboração de medidas intervencionistas, galgadas na vigilância, assistência e ensino de novas práticas educativas. Ao mesmo tempo, parece existir um grande esforço, ainda que intuitivo, para a superação dessa vigência, mas sem mobilização para que se vislumbrarem caminhos para outra prática, sobretudo por decorrência da organização dos serviços de saúde e da formação profissional, que não respaldam a construção do conhecimento sobre adolescência e sociedade como socialmente construídas, portanto, passíveis de modificação.

Sem conhecimento é impossível efetivar-se de identificações de casos, ações pertinentes específicas da situação, atuar de forma precisa, notificar corretamente, encaminhar, acompanhar; procedimentos que devem ser seguidos para, que de fato, seja efetiva a assistência a esse público.

.Às políticas agregam-se leis como os Estatutos da Criança e do Adolescente e a Política Nacional de Atenção Integral à Saúde de Adolescentes e Jovens, que destacam que a violência precisa ser enfrentada e uma forma de fazê-lo é sensibilizando, conscientizando, capacitando e 
formando pessoas dos mais diversos âmbitos da sociedade, mas, sobretudo, os alunos e profissionais do setor saúde, para onde convergem as vítimas desses eventos.

Por outro lado, esses aspectos são perpassados por fatores emocionais que comprometem uma melhor atuação. Podem se referir, dentre outras questões, a dificuldades de lidar com problemas relacionados a tabus e a atitudes de fuga frente a situações estressantes. No sentido de minimizar esses aspectos, os serviços poderiam criar redes de apoio e/ou equipes interdisciplinares para dar suporte ou subsídios às ações dosprofissionais

A possibilidade de tornar visível a violência o adolescente exige dos profissionais de saúde um "novo olhar" para a situação, como o olhar da Enfermagem e da Psicologia relatados no texto em questão. Assim, foi possível perceber que é necessário romper o muro de silêncio, retirando adolescentes, do abandono a que são lançados.

Entretanto, vale lembrar que, cada vez mais, em qualquer esforço de combate à violência torna-se imprescindível contar com uma ampla rede de apoio social estruturada, composta por instituições de diversos setores como educação, saúde, justiça, segurança, cultura e trabalho, governamentais e não governamentais, privilegiando a extensão dos direitos de cidadania, inclusive na vigência das relações interpessoais e familiares.

\section{Referências}

ANDRADE, Elisa Meireles et al.. A visão dos profissionais de saúde em relação à violência doméstica contra crianças e adolescentes: um estudo qualitativo. Saúde e Sociedade, São Paulo, v.20, n.1, p.147-155, 2011. Disponível em: www.repositorio.unifesp.br/handle/11600/6326. Acessoem jan de 2016.

ARAÚJO, M .B. S.; ROCHA, P.M. Trabalho em equipe: um desafio para a consolidação da estratégia de saúde da família. Ciência \& Saúde Coletiva, v.12, n.2, p:455-464, 2007. Disponível em: www.scielo.br/scielo.php?pid=S1413-81232007000200022\&script=sci...tlng. Acesso em jan de 2016.

ARAÚJO, M. F. S.; OLIVEIRA, F.M.C.. A Atuação do Enfermeiro na Equipe de Saúde da Família e a Satisfação Profissional. Revista Eletrônica de Ciências Sociais, setembro, n.14, p.03-14,2009. Disponível em: www.salesianolins.br/universitaria/avaliacao/no2/artigo30.doc. Acesso em novembro de 2015. 
BRASIL. Lei n 8069, de 13 de Julho de 1990. Dispõe sobre o Estatuto da Criança e do Adolescente e dá outras providências. Diário Oficial da República Federativa do Brasil, 1990.

. Ministério da Saúde. Notificação de maus-tratos contra crianças e adolescentes pelos profissionais de saúde: um passo a mais na cidadania em saúde. Brasília: MS, 2002.

Ministério da Saúde. Portaria n.1.162 de 7 de julho de 2005. Dispõe sobre a Política Nacional da Atenção Integral a Saúde de Adolescentes e Jovens, tendo como pilares normativos a Constituição Federal e o Estatuto da Criança e do Adolescente.

. Ministério da Saúde. Secretaria de Atenção à Saúde. Política nacional de atenção básica. Brasília: Editora do Ministério da Saúde, 2006.

2017.

Estatuto da Criança e do Adolescente. Lei 8.069/90, de 13 de julho de

CARMO, P.S; SAGAZ, V.R; A atuação do Psicólogo e Resiliência em Crianças Vítimas de Violência Sexual Intrafamiliar. Revista Trabalhos de Conclusão de Curso - Faculdade Sant'ana. Ponta Grossa, 2016. Disponível em: http://iessa.edu.br/revista/index.php/tcc Acesso em 05 de janeiro de 2016.

Conselho Federal de Enfermagem. Resolução COFEN n ${ }^{\circ} 240$ de 30 de agosto de 2000. Aprova o Código de Ética dos Profissionais de Enfermagem [resolução na internet]. Disponível em: http://www.hmjmj.com.br/wp-content/uploads/2011/01/ C\%C3\% B3digo-de-\%C3\%89tica-dosProfissionais-de-Enfermagem.pdf. Acesso em: dezembro de 2015.

Conselho Federal de Psicologia. (2015). Resolução CFP n 02/2015. Código de Ética Profissional do Psicólogo, Brasília, DF: CFP. Disponível em: https://site.cfp.org.br/wpcontent/uploads/2012/07/codigo-de-etica-psicologia.pdf. Acesso em jan de 2016.

COSTA, Glauce Dias da et al.Saúde da família: desafios no processo de reorientação do modelo assistencial. Rev. bras. enferm. [online]. 2009, vol.62, n.1, pp.113-118. ISSN 00347167. Disponível em: http://dx.doi.org/10.1590/S0034-71672009000100017. Acesso em janeiro de 2017.

DAVIM, R. M. et al. Adolescente/ Adolescência: revisão teórica sobre uma fase crítica da vida. Rev. Rene. Fortaleza, v. 10, n. 2, p. 131-140, abr./jun.2009. Disponível em: http://www.revistarene.ufc.br/vol10n2_pdf/a15v10n2.pdf. Acesso em dezembro de

DUTRA, E. Considerações sobre as significações da psicologia clínica na contemporaneidade. Estudos de Psicologia (Natal), 9, 381-387, 2008.

FERRARI, R. A. P., THOMSON, Z., MELCHIOR. R. Atenção à saúde dos adolescentes: percepção dos médicos e enfermeiros das equipes da saúde da família. Caderno de Saúde Pública, v. 22, n.11, p: 2491-2495, nov, 2006. 
FERRARI, R. A. P.; THOMSON, Z.; MELCHIOR, R. Adolescência: ações e percepção dos médicos e enfermeiros do Programa Saúde da Família. Interface - Comunicação, Saúde, Educação, v.12, n.25, p.387-400, abr./jun, 2008.

FERRAZ, M. I. R. et al..O cuidado da enfermagem a vítimas de violência doméstica.

GIL, A. C. Como elaborar projeto de pesquisa. São Paulo: Atlas, 2009.

GIL, Antônio Carlos. Métodos e Técnicas de Pesquisa Social. Editora atlas S/A São Paulo, 5 ed. 2006.

HABIGZANG, L. F. \& CAMINHA, R.M. Abuso sexual contra crianças e adolescentes: conceituação e intervenção clínica. São Paulo: Casa do Psicólogo, 2004.

HENRIQUE, D. B.; ROCHA, L. R.; MADEIRA, A. M. F. Saúde do adolescente: o significado do atendimento para os profissionais da atenção primária do município de Viçosa, MG. Revista Medica, Minas Gerais, v.20, n.3, p: 300-309,2010.

LIMA, M. A. D. S. et al..Atendimento aos usuários em situações de violência: concepções dos profissionais de unidades básicas de saúde. Revista Gaúcha de Enfermagem, dez, v.30, n.4, p:62532,2009 .

Disponível

em: http://www.scielo.br/scielo.php?script=sci arttext\&pid=S0103733120130003000Acesso em $28 \mathrm{de}$ janeiro de 2015.

LINARD, A.M. et al.Princípios do Sistema Único de Saúde:compreensão dos enfermeiros da Estratégia de Saúde da Família. Rev Gaúcha Enferm., Porto Alegre (RS), Mar,v.32, n.1, p:114-20, 2011. Disponível em: http://seer.ufrgs.br/RevistaGauchadeEnfermagem/article/view/12333. Acesso em 25 de agosto de 2016.

MACHADO, M. F. A. S.; VIEIRA, N. F. C.; SILVA, R. M.. Compreensão das mudanças comportamentais do usuário no Programa Saúde da Família por meio da participação habilitadora. Ciência \& Saúde Coletiva, v. 15, p. 1895-1897, 2010. Disponível em: http://www.scielo.br/scielo.php?script=sci_abstract\&pid=S141381232010000400027\&lng=pt\&nr $\mathrm{m}=$ iso. Acesso em 15 de janiero de 2017.

MARTINS, C. B. G. Maus tratos contra crianças e adolescentes. Revista Brasileira de Enfermagem julho-agosto,v. 63, n.4, p. 660-665, 2010. Disponível em: http://www.scielo.br/pdf/reben/v63n4/24.pdf. Acesso em fevereiro de 2016.

MARTINS, C. S. et al..A dinâmica familiar na visão de pais e filhos envolvidos na violência doméstica contra crianças e adolescentes. Revista Latino-Americana de Enfermagem setembrooutubro, v.15, n.5, 2007. Disponível em: http://www.scielo.br/pdf/rlae/v15n5/pt_v15n5a01.pdf. Acesso em Janeiro de 2015.

MINAYO, M. C. S. O desafio do conhecimento: pesquisa qualitativa em saúde. Rio de Janeiro: Abrasco/ São Paulo: Hucitec; 2007. 
MURTA, Scheila G.; MARINHO, Tanimar P. C. A Clínica Ampliada e as Políticas de Assistência Social: uma Experiência com Adolescentes no Programa de Atenção Integral à Família. Revista Eletrônica de Psicologia e Políticas Públicas Vol.1 No1, 2009. Disponível em: http://www.crp09.org.br/NetManager/documentos/v1n1a4.pdf. Acesso em 20 de setembro de 2016.

NUNES, C. B.; SATI, C. A.; OHARA, C. V. S; Concepções de profissionais de saúde sobre a violência intrafamiliar contra a criança e o adolescente. Revista Latino-Americana de Enfermagem janeiro-fevereiro, v.16, n.1, 2006. Disponível em: http://www.scielo.br/pdf/rlae/v16n1/pt_20.pdf. Acesso em 30 de janeiro de 2017

OLIVEIRA, M. T. de et al. Sub-registro da violência doméstica em adolescentes: a (in)visibilidade na demanda ambulatorial de um serviço de saúde no Recife-PE, Brasil. Revista Brasileira de Saúde Materno Infantil , v.11, n.1, p. 29-39, jan. / mar. 2011. Disponível em: http://www.scielo.br/scielo.php?script=sci_arttext\&pid=S1519-38292011000100004. Acesso em 30 de janeiro de 2017.

PIRES, A. L. D. ; S., M. C. O. ;MIYAZAKI. Maus-tratos contra crianças e adolescentes: revisão da literatura para profissionais da saúde. Arquivos de Ciências da Saúde v.12, n.1, p.42-9, jan-mar 2007. Disponível em: http://repositorio-racs.famerp.br/racs_ol/Vol-12-1/08\%20\%20id\%20102.pdf. Acesso em 29 de fevereiro de 2015.

PRATTA, E. M. M.; SANTOS, M. A dos. Família e adolescência: a influência do contexto familiar no desenvolvimento psicológicos de seus membros. Psicologia em Estudo, Maringá, v. 12, n. 2, p. 247-256, maio/ago. 2007. Disponível em: http://www.scielo.br/scielo.php?pid=S141373722007000200005\&script=sci_abstract\&tlng=pt. Acesso em 29 de fevereiro de 2015.

PRIULI, R. M. A.; MORAES, M. S. de. Adolescentes em conflito com a lei. Ciência \& Saúde Coletiva, v. 12, n.5, p: 1185-1192,2007.

RAPOSO, C. A Política de Atenção Integral à Saúde do Adolescente e Jovem: uma perspectiva de garantia de direito à saúde? Revista da Faculdade de Serviço Social da Universidade do Estado do Rio de Janeiro, v. 6, n. 23, 2009. Disponível em: http://www.epublicacoes.uerj.br/index.php/revistaempauta/article/view/450. Acesso em 27 de janeiro de 2017.

RESSEL, L. B. et al. Saúde, doença e vulnerabilidade para mulheres adolescentes. Escola Anna Nery Revista de Enfermagem, v. 13, n.3, p.552-57,2009. Disponível em: http://www.scielo.br/pdf/ean/v13n3/v13n3a14. Acesso em 27 de fevereiro de 2016

SALCEDO-BARRIENTOS, D. M. et al.. Violência doméstica e enfermagem: da percepção do fenômeno à realidade cotidiana. Avances enEnfermería, julio-dezembro, v.29, n. 2, 2011.

SALIBA, O. et al.. Responsabilidade do profissional de saúde sobre a notificação de casos de violência doméstica. Revista de Saúde Pública, v. 41, n.3, p.472-477, 2007. Disponível em: http://www.scielo.br/scielo.php?pid=S003489102007000300021\&script=sci_abstract\&tlng=pt. Acesso em 20 de janeiro de 2016. 
SILVA, D. M. P. Psicologia Jurídica no Processo Civil Brasileiro. São Paulo: Casa do Psicólogo, pags.39 a $45,2003$.

SILVA, L. M. P.; FERRIANI, M. G. C.; SILVA, M. A. L. Atuação da enfermagem frente à violência sexual contra crianças e adolescentes. Revista Brasileira de Enfermagem, Brasília, setout, v. 64, n.5, p: 919-24, 2011.

SILVA, L. M. P; et al. Violência doméstica contra crianças e adolescentes. Brasília: Ministério da Saúde; 2002. Disponível em: http://dtr2001.saude.gov.br /editora /produtos/ livros /pdf/03_1492_M.pdf. Acesso em: 15 de maio de 2012.

SILVA, M. B. G. M; TORNELI, A. L. N.; LACERDA, M. R. Instrumentos do cuidado humanizado de enfermagem: uma reflexão teórica. CogitareEnferm., v.8, n.1, p:59-64, 2003.

SILVA, Elisa Souza. Promoção da saúde do adolescente na atenção básica com ênfase na saúde sexual e reprodutiva. 2010.53 f. Trabalho de Conclusão de Curso de Especialização (Atenção Básica em Saúde da Família) Universidade Federal de Minas Gerais, Governador Valadares, 2003.

SOUZA, E. R. de. et al.. O tema violência intrafamiliar na concepção dos formadores dos profissionais de saúde. Ciência \& Saúde Coletiva, n.14, v.5, p. 1709-1719, 2009. Disponível em: http://www.scielo.br/scielo.php?pid=S1413-81232009000500012\&script=sci_abstract\&tlng=pt. Acesso em 20 de janeiro de 2015.

TRAVESSO, A. M.; PINHEIRO, V. S..Adolescência, saúde e contexto social: esclarecendo práticas. Psicologia \& Sociedade, v.14, n.2, p: 133-147, 2002. Disponível em: http://www.scielo.br/scielo.php?pid=S0102-71822002000200007\&script=sci_abstract\&tlng=pt. Acessoem 30 de julho de 2016.

WORLD HEALTH ORGANIZATION (WHO). Child abuse and neglect by parents and other caregivers. In: KRUG, E. G. et al. (edit.) World report on violence and health. Geneva: WHO, 2002. cap. 3 .

\section{Como citar este artigo (Formato ABNT):}

SENA, Brunna N. A. S. R.de; TEIXEIRA, Iasminny L.; AMORIM, Letícia F. de. A Violência Doméstica na Adolescência, sob o olhar da Enfermagem e da Psicologia. Id on Line Rev.Mult. Psic. 2018, vol.12, n.40, p.292-314. ISSN: 1981-1179.

Recebido: 17/03/2018

Aceito 22/03/2018 